\title{
Anti-Mullerian Hormone And Puberty Development On Girls And Adolescents Who Underwent Cancer Treatment
}

\section{Sarrah Ayuandari ( $\nabla$ sarrah.ayuandari@ugm.ac.id)}

Universitas Gadjah Mada Fakultas Kedokteran Kesehatan Masyarakat dan Keperawatan https://orcid.org/0000-0002-0595-4925

\section{Agung Dewanto}

Universitas Gadjah Mada Fakultas Kedokteran Kesehatan Masyarakat dan Keperawatan https://orcid.org/0000-0001-8403-0001

\section{Rizki Oktasari}

Universitas Gadjah Mada Fakultas Kedokteran Kesehatan Masyarakat dan Keperawatan

\section{Naafi Rizqi Rahmawati}

Universitas Gadjah Mada Fakultas Kedokteran Kesehatan Masyarakat dan Keperawatan

Nurulita Ainun Alma

Universitas Gadjah Mada Fakultas Kedokteran Kesehatan Masyarakat dan Keperawatan

\section{Kuky Cahya Hamurajib}

Universitas Gadjah Mada Fakultas Kedokteran Kesehatan Masyarakat dan Keperawatan

\section{Sri Mulatsih}

Universitas Gadjah Mada Fakultas Kedokteran Kesehatan Masyarakat dan Keperawatan

\section{Research Article}

Keywords: anti-Mullerian hormone, tanner, puberty, childhood cancer, fertility

Posted Date: July 21st, 2021

DOI: https://doi.org/10.21203/rs.3.rs-664100/v1

License: (c) (1) This work is licensed under a Creative Commons Attribution 4.0 International License. Read Full License

Version of Record: A version of this preprint was published at Archives of Gynecology and Obstetrics on January 19th, 2022. See the published version at https://doi.org/10.1007/s00404-021-06364-5. 


\section{Abstract}

Background: High survival rate of children diagnosed with cancer has led to a growing population of women with premature ovarian failure (POF) due to chemotherapy and radiotherapy. The POF process occurs due to the disruption of the Hypothalamic-Pituitary and gonadal axis followed by the delay of puberty development. Evaluation of reproductive function in children with cancer is essential to determine the fertility preservation plan. This study aimed to describe reproductive function in children and adolescents with cancer who received chemotherapy based on Tanner stage evaluation, menstrual cycle, and Anti-Mullerian Hormone (AMH) examination using Electrochemilumiscence Immunoassay (ECLIA) Kit.

Result: Twenty-three girls aged 12-18 years old and had menarche who underwent cancer therapy in January-August 2019 in Dr. Sardjito General Hospital were included in the study. Among them, 61\% girls had low AMH levels and were defined as Diminished Ovarian Reserve (DOR). There were two subjects with DOR who experienced delayed puberty. Regular menstrual cycle was reported in $65.2 \%$ subjects, while $21.7 \%$ encountered secondary amenorrhea.

Conclusion: Chemotherapy exposure impacted on DOR occurrence in $60.9 \%$ childhood and adolescence cancer. Moreover, it also altered menstrual regularity in $34.8 \%$ and delayed on puberty development in $8.7 \%$ subjects.

\section{Background}

Children diagnosed with cancer have a 5 -year survival rate of more than $80 \%$ [1]. The increased survival rate in children with cancer has led to a growing population of women with premature ovarian failure (POF) due to radiotherapy and chemotherapy exposure in cancer treatment [2]. POF is defined as menopause occurrence before 41 years old and it is marked by increased gonadotropin level and decreased steroid sex hormone [3]. Moreover, chemotherapy and radiotherapy exposure in childhood or adolescence can potentially disrupt pubertal development [4]. Therefore, education and counseling related to fertility preservation should be done in childhood cancer patients before receiving chemotherapy and radiotherapy.

POF in female children and adolescent can be evaluated clinically based on puberty development and menstrual history [5]. During puberty, there is growth spurt, sexual maturity, and attainment of reproductive capacity process [6]. Puberty is initiated by the release of pulsatile GnRH causing reactivation of the Hypothalamic-Pituitary and gonadal axis [7]. Therefore, the disruption of this axis that occurs due to tumors, surgery, radiation, and chemotherapy, which are gonadotoxic, can cause endocrine disturbances that lead to disruption of the puberty process [8]. This disruption of puberty can be measured with the Tanner Staging which is used to classify the development of secondary sex characteristics of children [9]. 
Reproduction function measurements in an adult woman can be done by measuring gonadotropin, estradiol, and progesterone levels. However, the Hypothalamus-pituitary-gonadal axis has not been activated in prepubertal girls, therefore those markers are impossible to be measured [5]. Anti-Mullerian Hormone (AMH) levels in woman can be detected from birth and continue to increase until reaching their peak in 25 years old [10]. AMH is a member of tumor growth factor-beta (TGF- $\beta$ ) produced by granulosa from preantral and small antral follicles [11]. AMH hormones can be used as a marker indirectly in ovary follicle reserves with the assumption that the numbers of preantral and small antral follicles are related to the number of primordial follicles [12]. Therefore, the AMH level can be used as an alternative parameter of ovarian follicle reserve in children and adolescents [13].

Evaluation of reproductive function in children and adolescents with cancer is essential to determine the fertility preservation plan [14]. Previous studies have stated the impact of chemotherapy and radiotherapy agents on fertility function. However, studies of ovarian follicle reserve and puberty development in children and adolescents are limited in practice. Therefore, this research aimed to describe the reproductive function in female children and adolescents with cancer, based on the Tanner evaluation, menstrual cycle, and $\mathrm{AMH}$ examination during chemotherapy.

\section{Methods}

\section{Study design}

This study used cross-sectional methods which conducted the data collection of AMH level and pubertal status during and after chemotherapy at a single point of time on patient with malignancy. The data collection was performed during January until August 2019 in the Pediatrics Department of Dr. Sardjito General Hospital, Yogyakarta, Indonesia.

\section{Subjects}

The study recruited girls diagnosed with hematological malignancy or solid cancer in Dr. Sardjito General Hospital who underwent chemotherapy during the study period. Patients were eligible to participate in this study when they met the following criteria: a) female children and adolescents aged 12-18 years old, b) who reached menarche, and c) parents have already given written informed consent to participate. However, children and adolescents who encountered critical states were excluded from the study.

\section{Data Collection}

Data collection targeted outpatients and inpatients in the Pediatrics Department. The demographic data were collected using a form to document subjects' data including: age of data collection, age at diagnosis, age of initial administration of chemotherapy, diagnosis, therapy onset, chemotherapy agent used, and menstrual cycle.

Regularity, cycle interval, and duration of menstruation were documented. Prolonged interval of menstrual cycle for more than 3 months was defined as secondary amenorrhea [16]. 
The AMH level was measured using blood sample and examined using AMH Electrochemilumiscence Immunoassay (ECLIA) Kit (Roche ${ }^{\mathrm{TM}}$ ). The sample analysis was conducted in accordance with the kit's protocol. The AMH levels were considered decreased and defined as Diminished Ovarian Reserve (DOR) if AMH level was $<1.52 \mathrm{mg} / \mathrm{L}[17]$.

Meanwhile, Tanner Staging was measured to examine reproductive function. Delayed puberty was defined as the absence of breast growth in a patient more than 13 years old or primary amenorrhea in a patient more than 15 years old.

\section{Data Analysis}

Data which had been documented were analyzed using Statistical Package for the Social Sciences (SPSS) 25.0 software (IBM Corp., Chicago). The demographic data, AMH level, menstrual pattern, and puberty development data were analyzed descriptively and summarized by mean or median and proportion value.

\section{Results}

\section{Demographic characteristics}

This research included 23 girls who underwent cancer therapy in January-August 2019 in Dr. Sardjito General Hospital. Three subjects died before finishing their scheduled therapy. The median of subjects' age, when checked for AMH level, was 14 years old. Table 1 shows the subjects' characteristics.

Among subjects, most of them had a hematological malignancy such as Acute Lymphoblastic Leukemia (ALL), Hodgkin lymphoma (HL), non-Hodgkin lymphoma (NHL), and chronic myelogenous leukemia (CML). Only two patients had a solid tumor in the form of osteosarcoma and ovarian cystoma. In this research, stratification for therapy risk was classified as low risk when received methotrexate, vincristine, actinomycin $\mathrm{D}$, vinblastine, mercaptopurine, or hydroxyurea and high risk when the patient received cyclophosphamide as their treatment regimen. No subject received radiotherapy.

Table 1. Subjects' characteristics 


\section{Characteristics}

Age (median)

Age at diagnosis (median)

Onset chemotherapy at AMH level measurement (median)

\section{Diagnosis}

ALL Standard Risk (ALL SR)

ALL High Risk (ALL HR)

ALL HR Meningeal

NHL T-Cell

$\mathrm{HL}$

Osteosarcoma

Ovarian cystoma

$\mathrm{CML}$

\section{The gonadotoxicity risk of chemotherapy agent}

Low gonadotoxicity

High gonadotoxicity

ALL: Acute Lymphoblastic Leukemia, HL: Hodgkin lymphoma, NHL: non-Hodgkin lymphoma, and CML: chronic myelogenous leukemia. $(n=23)$

14 years old (13-19)

12.9 years old $(7-17)$

64 weeks (3-289)
$1(4.3 \%)$

$8(34.8 \%)$

$3(13 \%)$

$1(4.3 \%)$

$2(8.7 \%)$

$1(4.3 \%)$

$1(4,3 \%)$

$6(26.1 \%)$

\section{AMH Level}

The level of AMH were measured for all subjects. From all subject, mean of AMH level was $1.43 \pm 1.36$ $\mathrm{ng} / \mathrm{dl}$ (Table 1). The highest AMH level was $4.23 \mathrm{ng} / \mathrm{dl}$, found on 18 years old girl who was received cyclophosphamide and undergone maintenance phase during the study period. Meanwhile the lowest AMH level was $0.01 \mathrm{ng} / \mathrm{dl}$, found on 13 years old girl who had been completed Indonesian ALL 2013 Protocol - Standard Risk.

Based on AMH level, $60.9 \%$ subjects experienced DOR and among them, 5 subjects received HRC and 9 subjects received LRC. Among patients who experienced DOR, 53\% patients encountered secondary amenorrhea and $46 \%$ patients had normal menstruation $(P=0.044)$. In DOR patients who had normal menstruation, most of them had regular cycle (Figure 1).

Table 2. Evaluation of reproduction function on children and adolescent cancer with chemotherapy treatment. 


\begin{tabular}{|ll|}
\hline Parameters & $\mathrm{n}=\mathbf{2 3}$ \\
\hline AMH level (mean) & $1.43 \pm 1.36$ \\
\hline Menstrual cycle & \\
\hline Menstrual duration (mean) & $6.2 \pm 0.4$ days \\
\hline Interval of menstrual cycle (mean) & $28.4 \pm 0.2$ days \\
\hline Menstrual regularity & \\
\hline Regular menstrual cycle (\%) & $65.2 \%$ \\
\hline Irregular menstrual cycle (\%) & $34.8 \%$ \\
\hline Delayed puberty development (\%) & $8.7 \%$ \\
\hline
\end{tabular}

\section{Menstrual cycle}

Among all subjects, average of menstrual cycle interval was 28 days (Table 2). Girls with cancer had average of menstrual duration around 6 days. Fourteen subjects in this research had regular menstrual cycle. Almost all subjects who had irregular menstrual cycle were classified as DOR. The longest interval of menstrual cycle which reached 35 days experienced by 14 years old girl received ALL 2016 Protocol Meningeal High Risk in maintenance phase. Five girls reported had experienced secondary amenorrhea. During menstruation, most of the symptoms that occurred were stomachaches and abdominal cramps in the initial cycles which was normal.

\section{Puberty development}

Girls with cancer on average reached menarche at 12 years old. Among all subjects, most of them had normal puberty development according to their age and only two subjects had delayed puberty development. Subjects who had delayed puberty were also found as DOR and received LRC during treatment.

\section{Discussion}

The increase of childhood and adolescence survival after cancer treatment in recent decades is associated with infertility in adulthood. This study was the first research which evaluated AMH level, puberty disruption, and Tanner Stage of girls and adolescents with cancer who underwent cancer treatment in Indonesia. The results were also used as background information for the initiation of fertility preservation services for childhood cancer patients who would receive gonadotoxic therapy in Indonesia.

Chemotherapy agents and radiotherapy could accelerate follicle depletion which would impact on fertility and premature menopause occurrence $[18,19]$. This is in accordance with the results of this study which found $61 \%$ of subjects had DOR. In this study, higher proportion of DOR experienced by subjects who 
received LRC. Meanwhile, a different result was found in a previous study by Lunsford et al. in 2013 which showed DOR occurrence was higher in the HRC group [19]. The different result might occur due to the difference in age of the subjects when receiving treatment, the younger age at diagnosis, and subjects had not undergone menarche. In females who reach menarche, there is activation of the Hypothalamicpituitary-gonadal axis. This condition causes a greater number of growing follicles, which are more susceptible to chemotherapy exposure, to undergo atresia. Damage of growing follicles during chemotherapy might occur due to disruption of granulosa cells division through inhibition of replicated DNA [20]. Depletion of growing follicles reduces the production of $\mathrm{AMH}$, which reduces inhibition of primordial follicle development. The increasing growth of follicles will increase follicle atresia and reduce ovarian reserve [21]. Therefore, younger patients who have not experienced menarche will have more follicular reserves and less frequently experience DOR [22].

The decreased growth of follicles during chemotherapy could also lead to menstrual disorders, such as transient or permanent amenorrhea [23]. This is consistent with recent study. Among patients with DOR, a patient experienced infrequent menstruation and five patients experienced secondary amenorrhea. Menstrual cycle pattern might be influenced by timing of chemotherapy within the patients' menstrual cycle. Patients who received chemotherapy during the follicular phase will experience increased risk of menstrual changes compared with those who received treatment during the menstrual phase. In addition, the duration of chemotherapy more than 6 cycles can also increase the risk of amenorrhea [24]. The amenorrhea relates to the chemotherapy regimen. In a previous study conducted by Casimo et al. in 2004, the use of cyclophosphamide regimen was associated with an increased risk of amenorrhea. However, it is also influenced by the accumulated dose and number of chemotherapy cycles which have been received [24].

Cancer treatment such as chemotherapy, cranium radiation or gonadal radiation can also increase the risk of puberty disruption due to the hypothalamus-pituitary axis disorder or ovarian failure [25]. The results of this study also found two cases of delayed puberty in patients with DOR. Research conducted by Muller in 2002 showed similar results in which childhood cancer patients in chemotherapy treatment alone did not affect the development of puberty [25].

This study was the first study conducted on our hospital for future identification of fertility and pubertal disturbance among children and adolescent with chemotherapy treatment. Our study has some limitations, such as small sample size and no follow up measurement of AMH level and other pubertal parameter after certain period of chemotherapy. A more comprehensive study with larger sample size and a specific AMH evaluation period should be done to confirm our findings. In the future study, evaluation of AMH level and menstrual cycle should be monitored before, during, and after chemotherapy to obtain a better description of the menstrual cycle changes.

\section{Conclusion}


In conclusion, chemotherapy exposure impacted on DOR occurance in $60.9 \%$ childhood and adolescence cancer. Moreover, it altered menstrual regularity in $34.8 \%$ and delayed on puberty development in $8.7 \%$ subjects.

\section{Abbreviations}

POF: premature ovarian failure; HRC: high-risk chemotherapy; LRC: low-risk chemotherapy; AMH: AntiMullerian Hormone; ECLIA: Electrochemilumiscence Immunoassay; DOR: diminished ovarian reserve; OR: odds ratio; Cl: confidence interval; SPSS: statistical package for the social sciences; ALL: Acute Lymphoblastic Leukemia; HL: Hodgkin lymphoma; NHL: non-Hodgkin lymphoma; CML: chronic myelogenous leukemia; DNA: deoxyribonucleic acid.

\section{Declarations}

Ethics approval and consent to participate

All procedures in this research had been approved by The Medical and Health Research Ethics Committee (MHREC) Faculty of Medicine, Public Health and Nursing Universitas Gadjah Mada - Dr. Sardjito General Hospital, Yogyakarta, Indonesia with reference number: KE/FK/0726/EC/2019. Written informed consent were obtained from every parents of the patients who participated in the study.

Consent for publications

Not applicable.

Availability of data and material

Data findings are available from corresponding author upon reasonable request.

Competing Interest

Authors declare no conflict of interest.

Funding

This study received funding from a research grant from Dr. Sardjito Hospital, Yogyakarta to cover AMH level examination cost, and did not receive any other funding from public or commercial sectors.

Authors' Contributions

SA was involved in the study design, data interpretation, manuscript writing and review; AD was involved in the study design and manuscript review; KH contributed to data analysis, data interpretation, manuscript writing, and editing; NA contributed to data analysis, data interpretation, manuscript writing, and editing; RO was involved in the data collection; NR was involved in the data collection; SM was 
involved in the study design and manuscript review. All authors have read and approved the final version of the manuscript.

Acknowledgements

The authors would like to express their gratitude to the staff of Klinik Bahasa for language assistance.

\section{References}

1. Gatta G, Zigon G, Capocaccia R, Coebergh JW, Desandes E, Kaatsch P et al (2009) Survival of European children and young adults with cancer diagnosed 1995-2002. Eur J Cancer 45:992-1005

2. Larsen EC, Muller J, Rechnitzer C, Schmiegelow K, Andersen AN (2003) Diminished ovarian reserve in female childhood cancer survivors with regular menstrual cycles and basal FSH $<10 \mathrm{IU} / \mathrm{I}$. Hum Reprod 18(2):417-422

3. Lee SJ, Schover LR, Partridge AH, Patrizio P, Wallace WH, Hagerty K et al (2006) American Society of Clinical Oncology recommendations on fertility preservation in cancer patients. J Clin Oncol 24(18):2917-2931

4. Issaoui ME, Giorgione V, Mamsen LS, Rechnitzer C, Birkebæk N, Clausen N, Kelsey TW, Andersen CY (2016) Effect of first line cancer treatment on the ovarian reserve and follicular density in girls under the age of 18 years. Fertil Steril 106(7):1757-162.e1

5. Hagen CP, Aksglaede L, Sørensen K, MainKM, Boas M, Cleemann L et al (2010) Serum levels of antiMullerian hormone as a marker of ovarian function in 926 healthy females from birth to adulthood and in 172 Turner syndrome patients. J Clin Endocrinol Metab 95(11):5003-5010

6. Patton GC, Hemphill SA, Beyers JM, Bond L, Toumbourou JW, McMorris BJ et al (2007) Pubertal stage and deliberate self-harm in adolescents. J Am Acad Child Adolesc Psychiatry 46(4):508-514

7. Herbison AE (2016) Control of puberty onset and fertility by gonadotropin-releasing hormone neurons. Nat Rev Endocrinol 12(8):452-466

8. Bozzola M, Albanese A, Butler GE, Cherubini V, Cicognani A, Caruso-Nicoletti M et al (2001) Unresolved problems in optimal therapy of pubertal disorders in oncological and bone marrow transplanted patients. Journal of Pediatric Endocrinology Metabolism 14:997-1002

9. Emmanuel M, Bokor BR (2020) Tanner stages [Updated 2020 Dec 18]. In: StatPearls [Internet]. StatPearls Publishing, Treasure Island (FL)

10. Lie FS, Visser JA, Welt CK, de Rijke YB, Eijkemans MJC, Broekmans FJ et al (2012) Serum antiMullerian hormone levels in healthy females: a nomogram ranging from infancy to adulthood. $\mathrm{J}$ Clin Endocrinol Metab 97(12):4650-4655

11. Dunlop CE, Anderson RA (2015) Uses of anti-Müllerian hormone (AMH) measurement before and after cancer treatment in women. Maturitas 80(3):245-250

12. Hansen KR, Hodnett GM, Knowlton N, Craig LB (2011) Correlation of ovarian reserve tests with histologically determined primordial follicle number. Fertil Steril 95:170-175 
13. Weenen C, Laven JS, Von Bergh AR, Cranfield M, Groome NP, Visser JA et al (2004) Anti-Mullerian hormone expression pattern in the human ovary: potential implications for initial and cyclic follicle recruitment. Mol Hum Reprod 10:77-83

14. Sonigo C, Beau I, Grynberg M, Binart N (2019) Anti-Müllerian hormone in fertility preservation: clinical and therapeutic applications. Clinical Medicine Insights: Reproductive Health 13:1-7

15. Angarita AM, Johnson CA, Fader AN, Christianson MS (2016) Fertility preservation: a key survivorship issue for young women with cancer. Front Oncol 6:1-10

16. Fraser IA, Critchley HOD, Broder M, Munro MG (2011) The FIGO Recommendations on terminologies and definitions for normal and abnormal uterine bleeding. Seminars in Reproductive Medicine 29(5):383-390

17. Cui L, Qin Y, Gao X, Lu J, Geng L, Ding L et al (2016) Anti-Müllerian hormone: correlation with age and androgenic and metabolic factors in women from birth to postmenopause. Fertil Steril 105(2):481485.e1

18. Brougham MFH, Crofton PM, Johnson EJ, Evans N, Anderson RA, Wallace WHB (2012) Anti-Müllerian hormone is a marker of gonadotoxicity in pre- and postpubertal girls treated for cancer: a prospective study. J Clin Endocrinol Metab 97(6):2059-2067

19. Lunsford AJ, Whelan K, Mccormick K, Mclaren JF (2013) Mullerian hormone as a measure of reproductive function in female childhood cancer survivors. Fertil Steril 101(1):227-231

20. Mitchison TJ (2012) The proliferation rate paradox in antimitotic chemotherapy. MBoC 23(1):1-6

21. Meirow D, Biederman H, Anderson RA, Wallace WHB (2010) Toxicity of chemotherapy and radiation on female reproduction. Clin Obstet Gynecol 53(4):727-739

22. Feigin E, Freud E, Fisch B, Orvieto R, Kravarusic D, Avrahami G (2008) Fertility preservation in female adolescents with malignancies. In: Cancer in Female Adolescents. USA Science Publishers Inc, Hauppauge, pp 38-101

23. Decanter C, Cloquet M, Dassonneville A, Orazio ED, Mailliez A, Pigny P (2018) Different patterns of ovarian recovery after cancer treatment suggest various individual ovarian susceptibilities to chemotherapy. Reprod Biomed Online 36(6):711-718

24. Cosimo SD, Alimonti A, Ferretti G, Sperduti I, Carlini P, Papaldo P et al (2004) Incidence of chemotherapy-induced amenorrhea depending on the timing of treatment by menstrual cycle phase in women with early breast cancer. Breast Cancer 15(7):1065-1071

25. Muller J (2002) Disturbance of pubertal development after cancer treatment. Best Pract Res Clin Endocrinol Metab 16(1):91-103

\section{Figures}




\section{Diminished Ovarian Reserve Normal Ovarian Reserve}

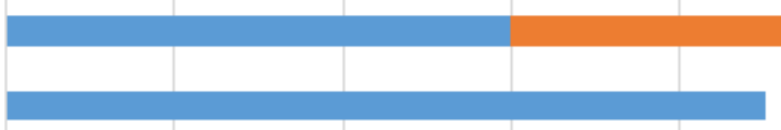

4

6

8
12

Number of subjects

normal Menstruation $\quad$ Secondary Amenorrhea

\section{Figure 1}

Proportion of DOR occurrence and menstruation changes. 